\title{
The Integral System
}

\section{Peter Petros}

Honorary Professor, Faculty of Medicine, University of New South Wales, Kensington, Sydney, Australia

\section{KEY WORDS}

Integral Theory Integral System diagnosis minisling ligaments connective tissue pictorial algorithm

\section{ABSTRACT}

The Integral System is a total care management system based on the Integral Theory which states 'prolapse and symptoms of urinary stress, urge, abnormal bowel \& bladder emptying, and some forms of pelvic pain, mainly arise, for different reasons, from laxity in the vagina or its supporting ligaments, a result of altered connective tissue.'

Normal function. The organs are suspended by ligaments against which muscles contract to open or close the their outlet tubes, urethra and anus. These ligaments fall naturally into a three-zone zone classification, anterior, middle, and posterior.

Dysfunction. Damaged ligaments weaken the force of muscle contraction, causing prolapse and abnormal bladder and bowel symptoms

Diagnosis. A pictorial diagnostic algorithm relates specific symptoms to damaged ligaments in each zone.

Treatment. In mild cases, new pelvic floor muscle exercises based on a squatting principle strengthen the natural closure muscles and their ligamentous insertions, thereby improving the symptoms predicted by the Theory. With more severe cases, polypropylene tapes applied through "keyhole" incision using special instruments reinforce the damaged ligaments, restoring structure and function.

Problems that can be potentially addressed by application of the Integral System

- Urinary stress incontinence

- Urinary urge incontinence

- Abnormal bladder emptying

- Facal incontinence and "obstructed evacuation" ("constipation")

- Pelvic pain, and some types of vulvodynia and interstitial cystitis

- Organ prolapse

Conclusions. Organ prolapse and symptoms are related, and both are mainly caused by laxity in the four main suspensory ligaments and perineal body. Restoration of ligament/fascial length and tension is required to restore anatomy and function.

\section{INTRODUCTION}

The Integral Theory states that prolapse and most pelvic floor symptoms such as urinary stress, urge, abnormal bowel and bladder emptying, and some forms of pelvic pain, mainly arise, for different reasons, from laxity in the vagina or its supporting ligaments, a result of altered connective tissue [1-5]. Birth related laxity, Fig. 1, compounded by ageing, are the principal causes of ligament laxity.

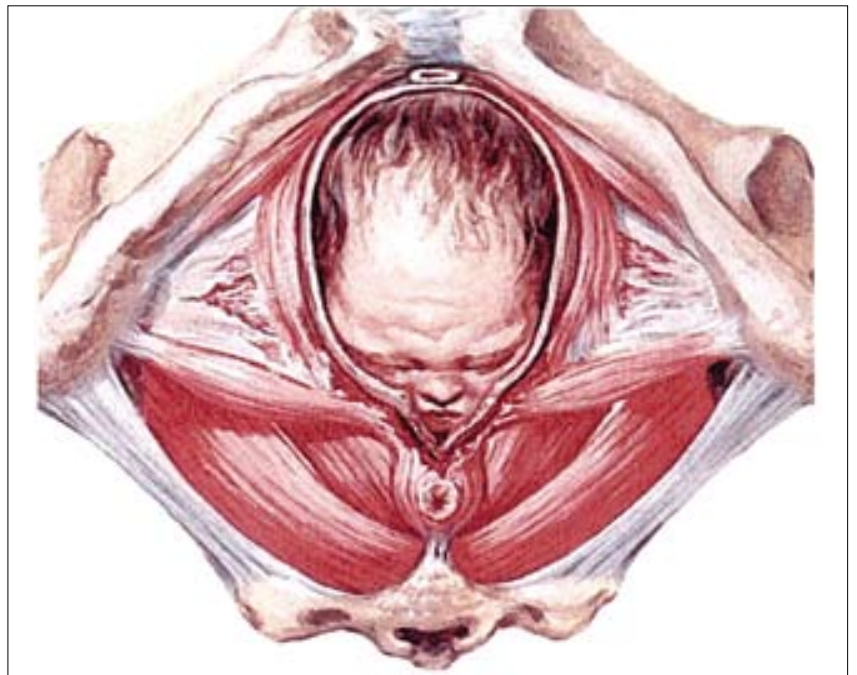

Fig. 1. Birth-related laxity. The diagram shows the baby's head severely stretching ligaments and other tissues in and outside the vagina. This may cause various degrees of looseness, prolapse of the bladder and bowel, and urine and bowel incontinence. Fundamental in any surgical treatment is the approximation of laterally displaced tissues, and the strengthening of damaged suspensory ligament(s).

The Integral Theory has evolved into the Integral System, which applies the damaged ligament theory to

- Function - the role of competent suspensory ligaments in organ support and function.

- Dysfunction - how damaged ligaments upset the musculoelastic control mechanism to cause prolapse and abnormal bowe and bladder symptoms.

- Diagnosis - how to diagnose which damaged ligaments are causing which prolapse and which symptoms.

- Treatment - in mild cases, new pelvic floor muscle exercises based on a squatting principle strengthen the natural closure muscles and their ligamentous insertions. With more severe cases, polypropylene tapes applied through "keyhole" incision using special instruments, reinforce the damaged ligaments, restoring structure and function.

\section{PART 1. THE DYNAMIC ANATOMY OF NORMAL FUNCTION}

\section{Bladder, bowel, and uterus}

Fig. 2 is a schematic view of the bladder, bowel and uterus with the woman in a sitting position. The organs are storage containers. The bladder stores urine, the uterus the fetus, and the rectum faeces. Each organ is connected to the outside by a tube, the urethra, which is about $4 \mathrm{~cm}$ long, vagina, which is $10-12 \mathrm{~cm}$ long, and the anus, about $4 \mathrm{~cm}$ long. The menstrual blood and fetus pass through the vagina. Urine and feces pass through the urethra and anus. Muscles compress these tubes to close them, and stretch them open for emptying.

\section{The importance of suspensory ligaments}

'Problems of bladder, bowel, prolapse, and some types of pelvic pain, mainly originate from the vaginal ligaments, not from the organs themselves' - Integral Theory 1996. 


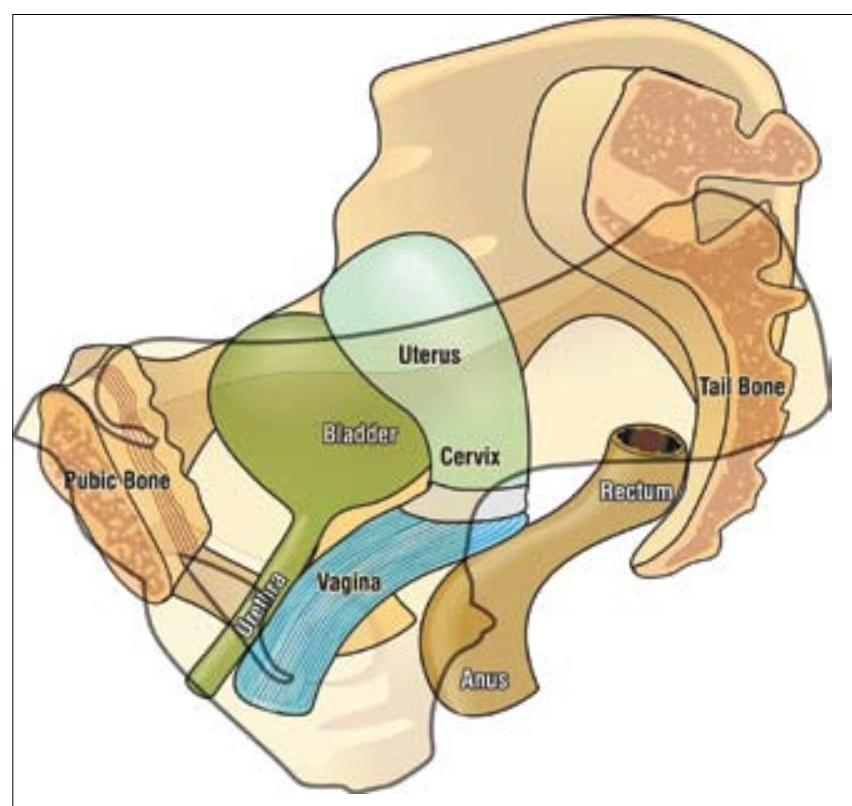

Fig. 2. The organs and their outlet tubes.

The bladder sits on top of the vagina, and is partly attached to it. Muscles pull against the ligaments to close or open the urethra. Therefore loose ligaments may weaken the muscle contraction to cause problems with closure (incontinence) or opening (evacuation of urine). The vagina, bladder, and bowel with no ligaments to suspend them, are but a blob of tissue, with no form, no structure, no strength, and no function.

A ligament is like a thick cord in a suspension bridge. In fact, the vagina is suspended exactly like a suspension bridge, with the ligaments above, Fig. 3, and the muscles (arrows) below, Fig. 4. The muscle forces (arrows) contract against the suspensory ligaments to give the bridge form and strength.

All the ligaments are attached to the vagina and/or uterus. The vagina supports the bladder situated above it, and the rectum situated below it, so anything which damages the vaginal structure, can also affect the bladder and rectum.

Separating the lower end of the vagina from the rectum is a solid mass of tissue, the perineal body (PB) complex which is about $4 \mathrm{~cm}$ long. If this is damaged, the rectum may bulge forwards into the vagina as a rectocoele.

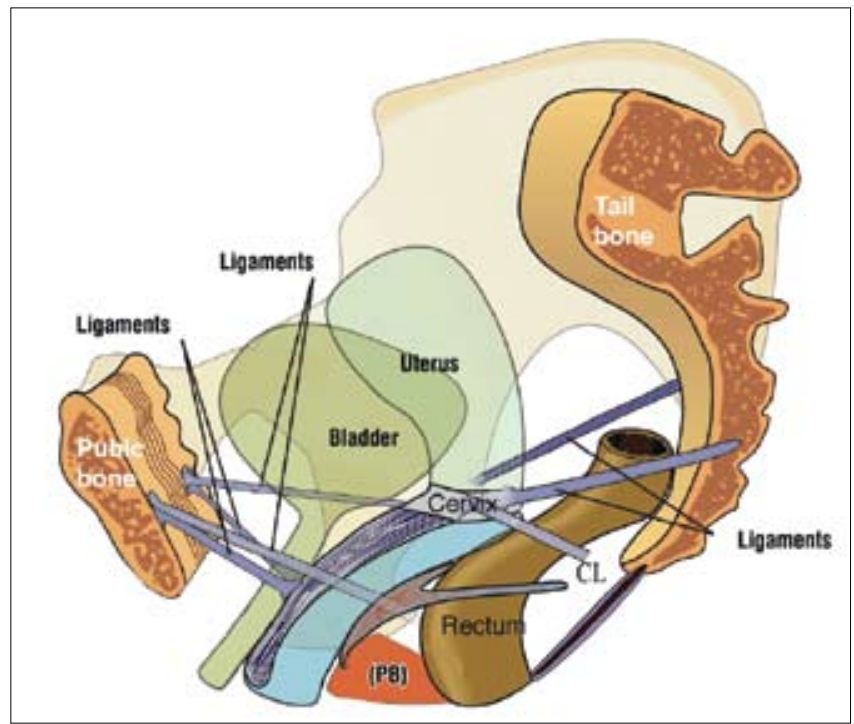

Fig. 3. Four ligaments suspend the organs from above like a suspension bridge. The perineal body (PB) supports the organs from below. $\mathrm{CL}=$ cardinal ligament.

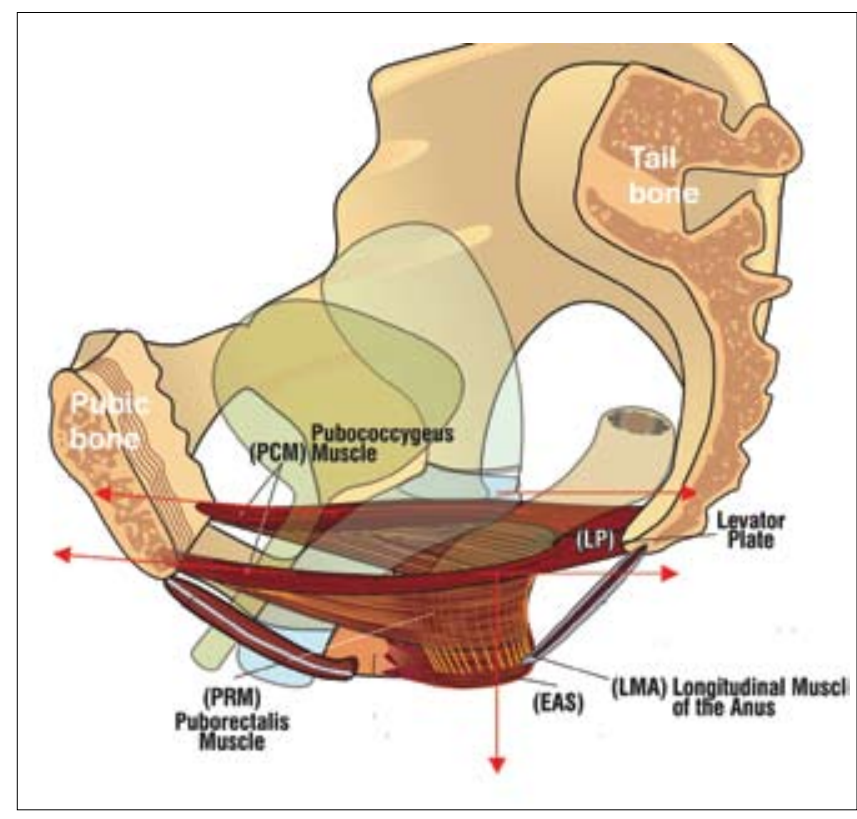

Fig. 4. The muscles support the organs, vagina, bladder, and bowel from below, and also, open and close them by three external directional muscle forces (arrows).

The uterus is an anchoring point for the ligaments - it needs to be preserved where possible

The role of the uterus in maintaining the structure and function of the pelvic floor is greatly underestimated. Some doctors routinely recommend removal of the uterus during surgery for prolapse. It is preferable to retain the uterus wherever possible, as many important ligaments are attached to it. During the menopause, the ovaries cease production of estrogen. Since estrogen is essential for maintaining the strength of the ligaments, the detrimental effects of hysterectomy on prolapse and incontinence become especially evident after the menopause. Hysterectomy reduces the blood supply to the cardinal and uterosacral ligaments, weakening them further. All these factors predispose to prolapse, and development of posterior zone symptoms [6].

The pelvic muscles (dark red), Fig. 4, have a dual function, organ support, and opening and opening and closure of urethra and anorectum. They extend from the coccyx to the pubic bone,



Fig. 5. An external striated muscle opening and closure mechanism. The red lines represent the pelvic muscles. Fibromuscular extensions from these muscle fibers loop around the urethra and anorectum to activate closure and opening. 


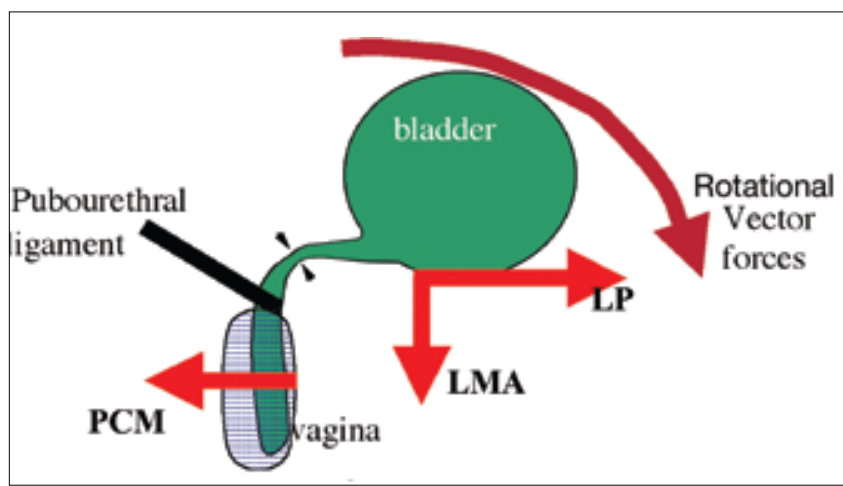

Fig. 6. The mechanism for urethrovesical closure. Backward/downward muscle vector forces (arrows) stretch the proximal urethra around the pubourethral ligament, narrowing and kinking it; a forward vector stretches the suburethral hammock forwards against the pubourethral ligament for distal urethral closure. $\mathrm{LP}=$ levator plate; $\mathrm{LMA}=$ longitudinal muscle of the anus; $\mathrm{PCM}=$ anterior portion of pubococcygeus muscle.

and contract to support the vagina, bladder, and bowel from below. The red arrows indicate the directions where the muscles contract, backwards to open these organs, forwards to close them.

An external striated muscle opening and closure mechanism, Fig. 5. [7, 8, 9-17].

Put simplistically, when the muscles pull backwards (blue arrows), the urethra and anus are pulled open, vastly decreasing intracavity resistance to the $4^{\text {th }}$ power, so that the woman can quickly and easily evacuate her urine and feces; when the muscles pull forwards* (black arrows), the urethra and anus are closed by a vast increase in resistance to the $4^{\text {th }}$ power. Normally all the organs, even the vagina, are kept in the closed position by slow-twitch muscle contraction.

*The closure mechanism, Fig. 6, is a little more complex than that depicted in Fig. 5, involving a distal and proximal mechanism for closure of the urethral and anal tubes [7-10].

How damaged ligaments may cause incontinence or emptying disorders. With reference to the suspension bridge analogy, the pelvic muscles pull against the ligaments.

So if the suspensory ligaments are loose, the muscle strength weakens, and may not be able to keep the bladder or bowel emptying tubes closed. As a consequence of this, a patient may feel a leakage of urine, wind, or faces, "incontinence". Another related condition is failure to close the vaginal tube, so water may enter the vagina during swimming, or complain of vaginal flatus. If the damaged ligaments do not allow the muscles to open these same emptying tubes, a patient may have to strain to empty her bladder or bowel, "evacuation disorder" or "emptying disorder". Fig. 7.

The brain and its nerves - a sophisticated feedback system,

The brain works like the computer at a big telephone exchange, with afferent and efferent nerves connected to the bladder, the vagina, bowel, striated and non-striated muscles. Organ sensors send signals to the brain to inform it as to what is happening. The brain receives and processes these signals, and depending on what is required, sends out orders via efferent nerves to open or close the organs, and to regulate muscle tone, the key factor in these functions. Most of this coordination occurs in "automatic mode". The patient is not aware of what is happening. The Theory regards urge symptoms, frequency, nocturia, and urodynamically diagnosed detrusor overactivity (DO) as differing expressions of a prematurely activated micturition reflex [18]. In a 1993 experiment, the sequence of events in a group of patients who had urodynamically diagnosed detrusor overactivity (DO) and who lost urine with a provocative hand-washing test was found to be identical with what occurs during normal micturition, a sensation of urgency, followed by urethral relaxation, detrusor contraction, and urine loss [18]. In a 1999 experiment, a low compliance bladder was deemed consistent with a partially controlled prematurely activated micturition reflex, which worked via a chaotically (non-linear) controlled neurological feedback system [19]. In the same experiment, it was found possible, in some patients, to temporarily control DO with gentle support of the stretch receptors "S", Fig. 7. The essential role of intraurethral resistance in urine flow and generation of detrusor pressure was explored with bench pressure/flow experiments, mathematical and clinical models [20, 21]. These experiments proved that because urethral resistance varied exponentially with the $4^{\text {th }}$ (laminar flow) or $5^{\text {th }}$ power (non-laminar flow) of the radius, the micturition detrusor pressure was entirely a function of the urethral diameter, reducing to zero at a given diameter and a given flow rate $[20,21]$. This explains the frequent observation of urine leakage during urodynamic testing at a zero detrusor pressure. This phenomenon can only be explained by a prematurely activated micturition reflex causing the pelvic floor muscles to actively open out the urethral outflow tract, as demonstrated by video xray and EMG studies $[7,8]$. It cannot be explained by other hypotheses, such as damage to afferent nerve tracts.

An anatomical basis for all aspects of urodynamics (cough transmission ratio "CTR", Maximal Urethral Closure Pressure "MUCP", detrusor overactivity "DO", Flow) and how morphology and such urodynamic results can be altered by digital support of

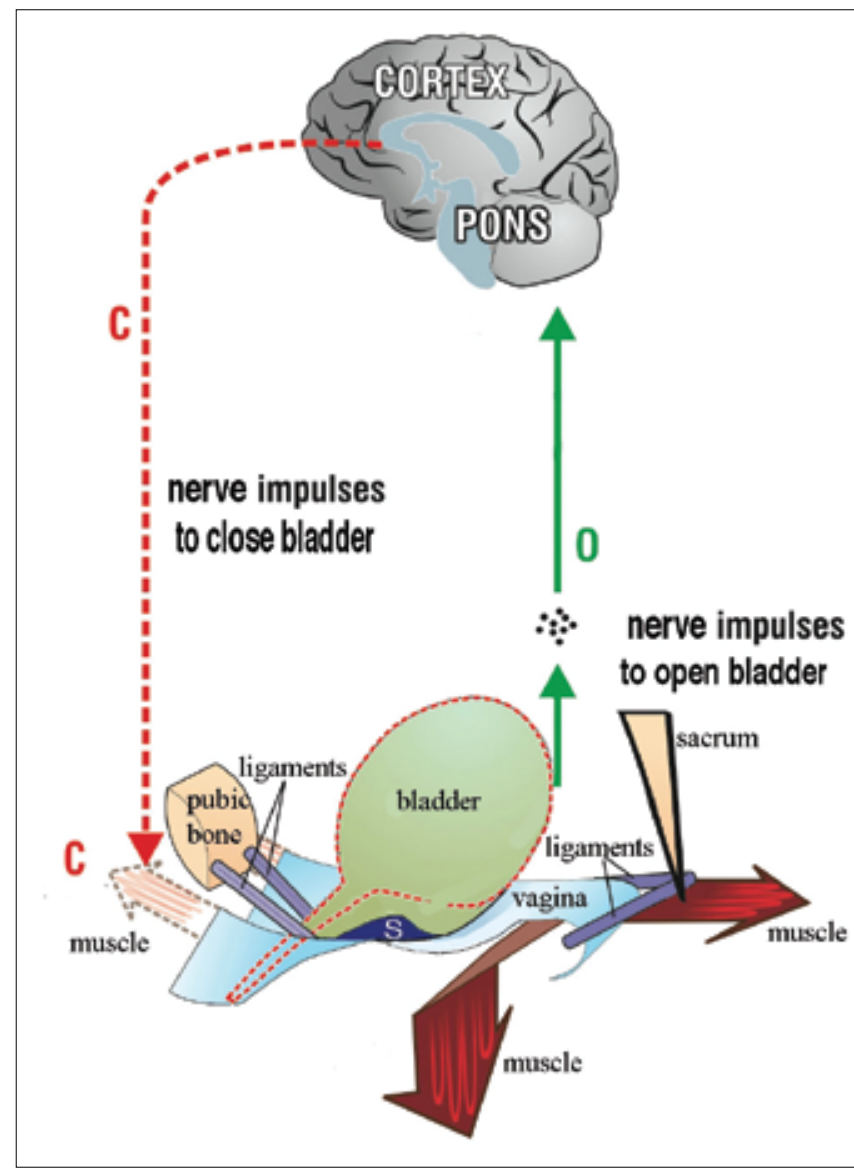

Fig. 7. The cortex of the brain gives directions for closure (C), and opening (0). Stretch receptors "S", at the base of the bladder sense when the bladder is full and send impulses to the brain. Depending on the situation, the brain sends directions either for closure $(\mathrm{C})$, or opening (0). Like instructions from the or chestra conductor, these directions, " $\mathrm{C}$ " and " 0 ", engage all the muscles, nerves, ligaments, and tissues required for each function. The Pons, a lower part of the brain, works as a coordinating station. 
specific connective tissue structures ("simulated operations") is discussed further in Chapter 6 of the textbook, "The Female Pelvic Floor" [22]. A major consequence of these concepts is that urgency (and DO) at least in the female, may be caused by the inability of the vaginal membrane to support the stretch receptors "S", Fig. 7. It follows from this that unstable bladder symptoms are potentially curable surgically by restoring the tension of the anterior vaginal wall, by repair of the suspensory ligaments of the vagina $[5,23]$ (see Part 4). Sometimes, a patient may actually instruct the brain. For example, if it is inconvenient to empty the bladder, the muscles can be pulled upwards to control urgency, a well known ploy for women who develop urge while shopping, "cross your legs and squeeze upwards". The "squeezing" stretches the vaginal membrane, to support the stretch receptors "S", Fig. 7, reducing the afferent flow of impulses to the cortex, and reversing the activation of the micturition reflex. This maneuvre would not work if the hypothesis of afferent nerve tract damage was valid. Pushing down assists emptying urine and faces by opening out the outflow tract. During intercourse the vagina can be narrowed by pulling the muscles upwards. This action grips the penis, and increases the sensation for both partners.

\section{PART 2. DYSFUNCTION - THE ROLE OF LAX LIGAMENTS IN THE CAUSATION OF SYMPTOMS AND PROLAPSE}

\section{The structure of ligaments}

A ligament is a complicated contractile structure which needs to be both elastic and strong while having the ability to contract or relax according to whether the urethra and anus are being closed or opened. It relies on its collagen content for strength, elastin for flexibility, smooth muscle for contractility, and nerves to coordinate all these functions. Collagen fiber work like the steel rods in cement. Single collagen fibres are "glued" together to give ligaments strength. The elastin content gives them elasticity. It is the change in collagen that is the ultimate cause of prolapse and incontinence.

How ligaments are stretched and damaged during pregnancy and labour

Muscles pull against the ligaments that support the bridge. If the ligaments are stretched and loosened during childbirth, as in Fig. 1, a patient may develop a prolapse, a "dragging" pain low in the abdomen, bladder symptoms, for example urgency, frequency, nocturia, or even problems with bowel emptying or fecal incontinence.

Commencing 6 months before childbirth, the "glue" between the collagen rods begins to soften in response to hormones from the placenta. This explains the onset of bladder, bowel, and pain symptoms at this time. Some 24-48 hours before delivery, however, this softening accelerates, and the collagen rods lose 95\% of their strength [24]. During delivery, the baby's head greatly stretches these collagen rods. Of course, the rods "re-glue" soon after delivery, but often they "reglue" in a loose and extended position. Neither the ligaments nor the muscles can now work properly, and this may lead to prolapse of the uterus, cystocele, rectocele, and a wide range of bladder, bowel and pelvic pain symptoms. Women who have had Caesarian sections may also become incontinent, but they have less stretching, and therefore, fewer problems than vaginal delivery patients. Loose ligaments may occur in women who have never had children. Such women are born with loose ligaments, or they may have a congenital defect in their collagen. All these conditions are potentially curable by creation of artificial ligaments, as will be explained in Part 4.

The effect of age and menopause on urinary \& bowel symptoms

Both collagen and elastin deteriorate markedly after menopause, which explains the vast increase in prolapse and incontinence that

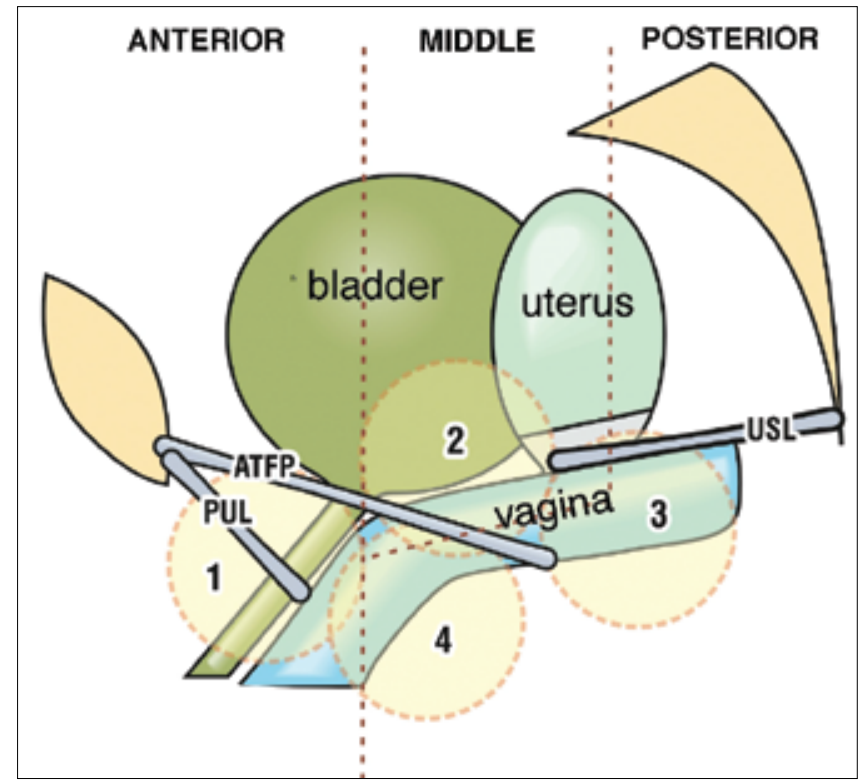

Fig. 8. The baby's head (circles) may damage the ligaments and vaginal tissues to varying degrees as it descends through the vagina to cause stress incontinence'1', cystocele '2', uterine/apical prolapse '3', and rectocoele '4'. PUL = pubourethral ligament; ATFP = arcus tendineus fascia pelvis; USL = uterosacral ligament. Not shown are cardinal ligament (Middle Zone) and Perineal Body (Posterior zone) [33].

occurs after this event [25]. A partially damaged ligament which is only just functioning before the menopause, may lose enough collagen after it, to "give way". This looseness may result in organ prolapse, abnormal symptoms, or both. The estrogen hormone replacement therapy ("HRT") helps to slow down the degeneration of collagen, though it cannot reverse damage (for example incontinence) once it has occurred, as the suspensory ligament(s) have already been stretched to the point where the muscle contractility is diminished due to the lax insertion point $[27,28]$. According to Gordon's Law, a muscle contracts efficiently only over a finite distance [29]. If the muscle insertion points, the pelvic ligaments, are loose, part of the muscle contraction is wasted in stretching the loose ligament. Therefore neither opening nor closure, Fig. 5 , can be adequately accomplished by the relevant muscles. Such dysfunction is perceived as symptoms, Fig. 9: inadequate closure = incontinence (urinary and fecal); inadequate evacuation = constipation and urinary retention/emptying difficulties; or inadequate stretching of the vaginal membrane causes "S" Fig. 7 to fire off prematurely= urgency, frequency nocturia.

As the problem is mechanical, no amount of hormonal therapy can repair a ligament that was sufficiently damaged to cause dysfunction. Though oral or injectable estrogens may be associated with an apparent increased risk of breast cancer, this has to be weighed against their benefits, suchus prevention of osteoporosis, hip fractures, thickening of the vaginal wall in sexually active patients, even perhaps prevention of heart disease. Vaginally inserted estrogen tablets are, however, considered safe, as they act locally, and thus are advantageous for every post-menopausal woman, even those of the most mature age.

\section{Site of damage and its consequences}

The circles in Fig. 8 represent the baby's head descending through the vagina during childbirth. This may stretch and loosen the ligaments (thick grey lines) in the three zones of the vagina. These are, Anterior Zone (meatus to bladder neck), Middle Zone, (bladder neck to cervix), and the Posterior Zone (cervix to perineal body). The numbers 1-4 indicate damage to specific ligaments that may cause: 
1. Stress incontinence

2. Cystocele

3. Prolapse of the uterus

4. Rectocele

It is evident that a head descending down a vulnerable vaginal canal, Fig. 8, is unlikely to damage just one single structure. All structures, 1-4, Fig. 8, will be damaged to a greater or lesser extent. This explains appearance of a cystocele, for example, months or years after apparently successful surgery for prolapse of the uterus.* Further prolapse can occur in perhaps 30-50\% of cases after a successful vaginal repair. The problem is that once the vaginal tissues are damaged, it is difficult to fully repair them. It is like repairing frayed cloth. The surgeon repairs one area, only to see it give way in another area. That is why we have to create artificial ligaments by using tapes.

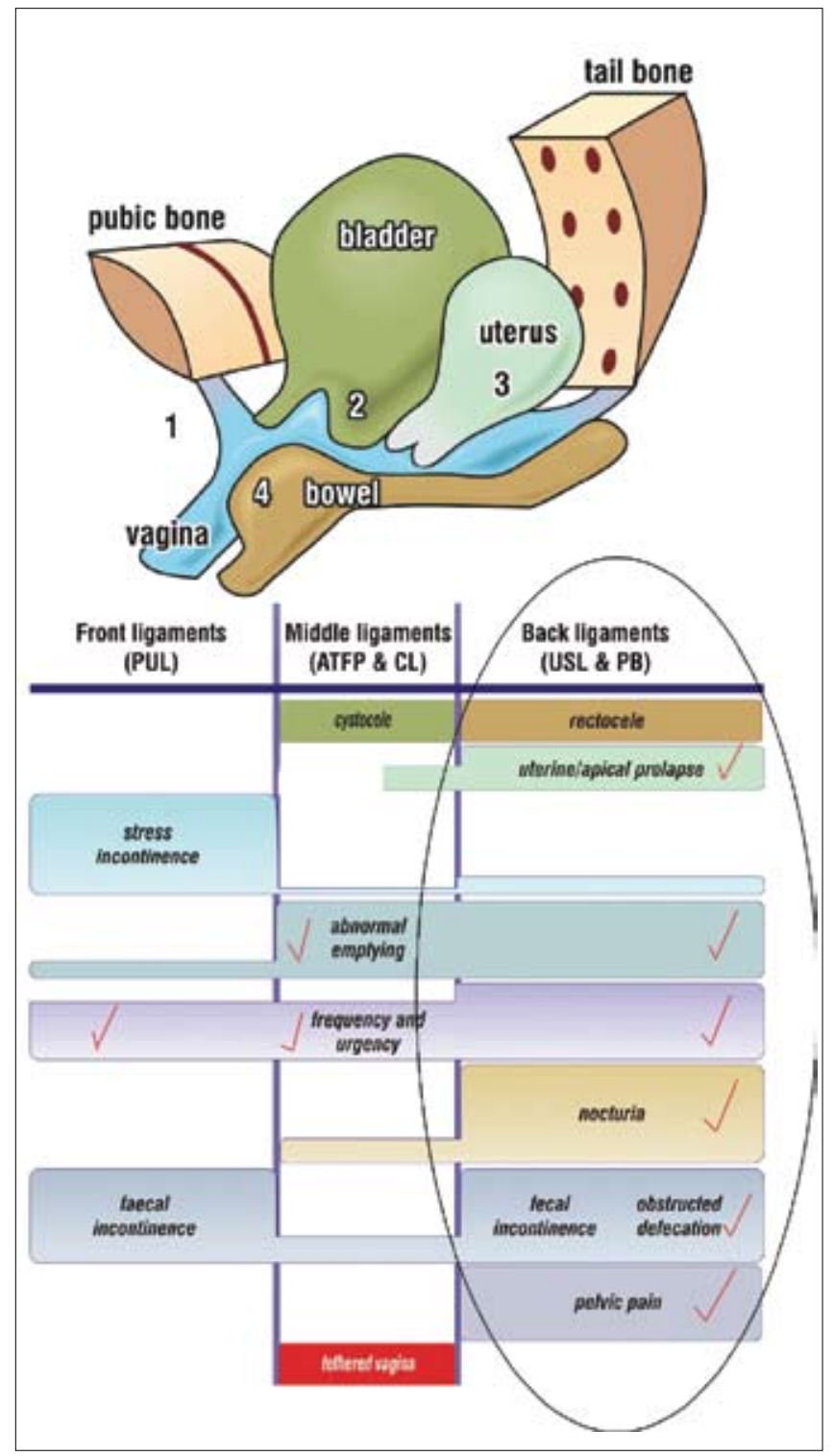

Fig. 9. Pictorial Diagnostic Algorithm relates prolapse (cystocoele "2", rectocele "4" and uterus " 3 "), to symptoms. Both prolapse and symptoms are caused by looseness in the suspensory ligaments and their associated tissues. The anterior (pubourethral) and posterior (uterosacral) ligaments are in purple. The middle ligaments (ATFP\& cardinal) are not shown in this diagram. There are three columns, one for each ligament group and the symptoms and prolapses (lumps) associated with damage to these ligaments. In patients who have urgency, grouping of symptoms is the key to diagnosing the zone of damage, as any zone may cause urgency. In this patient, the symptoms (ticked) indicate damaged posterior ligaments (uterosacral).
*The same rationale holds for de novo urgency after midurethral slings - the abdominal forces are diverted to subclinically damaged middle or posterior zones, with the de novo appearance of not only urgency, but other problems such as pelvic pain, abnormal emptying, nocturia, depending on the site of damage, Fig. 9.

The Role of Damaged Connective Tissue in the Pathogeneses of stress incontinence and Intrinsic Sphincter Defect

The Integral Theory does not distinguish between any classifications for stress incontinence, for example "urethral hypermobility", Type I, Type II etc. Rather it seeks to explain pathogenesis strictly in terms of anatomical defects in the connective tissue attachments of the urethra, the pubourethral ligaments that attach the urethra to the posterior surface of the pubic bone, the external ligaments to the anterior surface, and the suburethral vagina. Urine leakage as a consequence of laxity in these ligaments is therefore mainly a mechanical phenomenon except if there is accompanying urgency (see Diagnosis section). The main symptom with pubourethral ligament laxity is urine loss with stress. The main symptom with external urethral ligament laxity is urine loss on sudden movement with the accompanying sensation of a "bubble" escaping. This is a hitherto unrecognized cause of urine leakage after midurethral sling surgery, which can be cured by surgically reinforcing the external ligaments either directly or with a prepubic sling.

In the normal patient, three directional muscle forces stretch the trigone against the pubourethral (PUL) and external urethral ligaments (EUL) to narrow the urethral lumen and cut off the venous return so that the vascular plexus (Cresta Urethralis) in the posterior urethral wall swells into a horse-shoe shaped cavity in the anterior urethral wall. The horseshoe muscle, "rhabdo sphincter", contracts to seal the lumen. All these structures have connective tissue components that insert into the connective tissue of the vagina, pubourethral, and external ligaments.

Childbirth stretches these connective tissue components and ageing causes atrophy. Elastin begins to diminish in a female from her mid-twenties [25]. This weakens the connective tissue of PUL, EUL, vagina, the urethral wall, and vascular plexus. The urethral lumen loses its passive closure forces and dilates. The pubococcygeus (PCM) and the horseshoe muscles insert into what is now lax connective tissue. As the connective tissue of the vagina and PUL atrophies, these muscles lose more contractile strength and may even atrophy to the fatty tissue extreme described by Huisman [30]. The combination of the diminished closure forces and the dilated lumen lower the intraurethral pressure: "intrinsic sphincter defect". Intraurethral pressure, as measured in one segment of the urethra, is equal to all the forces impacting on that segment divided by the area over which the forces are exerted (Pressure $=$ force/area). Pressure per se is not an index of incontinence, nor does it necessarily predict poor surgical results.

Equivalent cure rates for patients with a low intraurethral pressure ("intrinsic sphincter defect") and high urethral pressures have been achieved after a midurethral minisling where attention was paid to also tighten the EUL and suburethral vagina concomitantly with insertion of a midurethral sling [31].

A cystocele "balloons" out from above. The cause is damage to the middle ligaments (ATFP and/or cardinal ligaments) and the anterior wall of the vagina.

A rectocele balloons out from below. Separating the lower end of the vagina from the rectum is the perineal body, a major supporting structure, as it occupies 50\% of the posterior vaginal wall. A rectocele, may be caused by damage to the uterosacral ligaments (high rectocele), and/or rectovaginal fascia \& perineal bodies (mid \& low rectocele. 
Uterine prolapse is caused by damage to the cardinal and uterosacral ligaments, which lengthen so that the uterus descends into the vaginal canal.

\section{A perspective on organ prolapse}

The organs bulge to varying degrees. Clearly a severe prolapse, such as the uterine prolapse above, requires treatment. If the bulge is minor, and there are no associated symptoms, there is no need for treatment. However, a patient may have severe symptoms which may require treatment, even though the prolapse is minor.

\section{PART 3. DIAGNOSIS}

Symptoms are very important in the Integral System. Because symptoms are usually grouped, it is possible to diagnose which ligaments are lax from the history

\section{Symptoms - what they mean}

A symptom is a warning bell from the brain that something is wrong with some part of the body. As regards the pelvic floor, many bladder and bowel symptoms are secondary to damage in one or more related ligaments, not from the organ itself. The challenge is to find which ligaments are causing the problem.

The Diagnostic Algorithm (Fig. 9) indicates which ligaments are causing symptoms and prolapse

The following Diagnostic Algorithm is a simplified version of that published in the textbook, "The Female Pelvic Floor" $2^{\text {nd }}$ Edition (2006), Springer, Heidelberg. To use this diagram, a tick is placed in every column that describes a patient's symptoms, and the diagram will indicate the zone of damage, anterior, middle, or posterior ligaments.

NOTE: A prolapse may occur with no accompanying symptoms, and major symptoms may occur with only minimal prolapse. Whether symptoms such as pelvic pain, nocturia, urgency and frequency occur or not depends on the sensitivity of stretch receptors and nerve endings.

How to use the Diagnostic Algorithm. There are 3 zones, each with specific symptoms correlating to connective tissue defect(s). Simply tick every column which describes a symptom. One needs to tick all the relevant columns for symptoms such as urgency and emptying, which may occur in more than one column. In such cases, other associated symptoms, which are more specific, will help to guide the diagnosis. For example, I have found that nocturia and pelvic pain are specific for the posterior zone, and stress incontinence for the anterior zone. The middle zone has only two symptoms, urgency and abnormal emptying, neither of which is specific for the middle zone.

\section{Symptoms occur in groups - an aid to diagnosis}

For example, urgency symptoms are indicated in all three columns, Fig. 9. Symptom grouping is the only way we can deduce which column (ligament) is causing the urgency. Fortunately, urgency almost always occurs in tandem with at least one other symptom.

Diagnosis of anterior zone defect. The main symptom is stress incontinence, which occurs because of laxity in the pubourethral ligament [1]. However, if the patient also has urgency ("mixed incontinence"), and no other symptoms from the middle or posterior zones such as pelvic pain, nocturia, abnormal emptying, she would be advised that she has a high probability of cure of both her stress and urge symptoms.

Diagnosis of middle zone defect. If a patient has a cystocele, urgency and abnormal emptying with no other symptoms, and no other prolapse, it is likely that the cystocele is causing both problems.
Diagnosis of posterior zone defect If a patient has urgency and abnormal emptying, nocturia, and pelvic pain, it is likely she has lax uterosacral ligaments, even if there is minimal prolapse evident on vaginal examination. In an experience spanning two decades and thousands of cases, I have rarely found an exception to this. If however, the patient also has a cystocele, it is possible that there it may also be contributing to two of the symptoms, urgency and abnormal emptying.

Characteristics of pain* caused by posterior ligament looseness

- Low abdominal 'dragging' pain

usually unilateral, often right-sided

- Low sacral pain (pain near the tailbone)

- Pain on deep penetration with intercourse

- Low abdominal ache the next day after intercourse

- Tiredness

- Irritability

- Pain worsens during the day and is relieved by lying down

- Pain is reproduced on pressing the cervix or the posterior wall of the vagina if a patient has had a hysterectomy.

*There is growing evidence that some types of introital hypersensitivity ('vulvodynia') and perhaps even some types of bladder pain ('interstitial cystitis) may be part of the posterior zone symptom complex in figure 9 , nocturia, urgency, and abnormal bladder emptying [32-34].

\section{Characteristics of "vulvodynia"}

A burning pain over the entrance of the vagina and anus, with extreme sensitivity to touch. This condition is often associated with dragging lower abdominal pain and sometimes painful bladder conditions.

\section{Characteristics of bladder emptying difficulty}

Typical symptoms are a slow stream, starting and stopping, dribbling after micturition has been completed, and a feeling that the bladder has not emptied. Often such patients have chronic urinary infections. The pathogenesis of voiding dysfunction (abnormal emptying) ultimately relates to an inverse exponential relationship between urine flow and urethral diameter (Poisseuille's Law), to the $4^{\text {th }}$ power for laminar flow, and the $5^{\text {th }}$ power for nonlamnar flow $[20,21]$. For example, if the backward muscle forces, which actively open out the urethra during micturition, (blue arrows, Fig. 5), [7, 8], cannot function adequately because of a lax insertion point into the uterosacral ligaments (USL), or because of a large cystocele, the urethra cannot be actively opened out (Gordon's Law [29]), so that a much higher micturition pressure is required. For example if a urethral diameter "D" which requires an emptying pressure of $160 \mathrm{~cm} \mathrm{H}_{2} \mathrm{O}$ at a given flow rate can be opened out to $2 \mathrm{D}$, the micturition pressure required to empty is reduced by at least 16 times $(2 \times 2 \times 2 \times 2)$ to $10 \mathrm{~cm} \mathrm{H}_{2} \mathrm{O}[7,8]$. If because of lax USLs or cystocele this external opening mechanism is deficient, the increased resistance to flow that is encountered results in a slower evacuation rate ("slow flow", "poor stream"). Furthermore, because of deficient "grip" on the ligaments, the patient may have to activate her muscles several times to overcome the natural elastic closure of the urethra, giving rise to the symptoms of "stopping and starting".

\section{Characteristics of fecal incontinence}

Typical symptoms, in order of severity, are uncontrolled wind loss, liquid soiling, and solid fecal soiling. There are two main categories, patients with faecal incontinence caused by an anal sphincter torn at childbirth, and another where no obvious cause can be found. The anal sphincter constricts the lower part of the anus. It is what a patient feels when she contracts her muscles to delay bowel 
emptying. Where no obvious cause can be found, it is called "idiopathic incontinence" [9-17]. It is "idiopathic incontinence" taht is potentially curable by reconstructing the anterior or posterior ligaments [45-47]. The anorectum has an external opening mechanism for anorectal closure and fecal evacuation analogous to the bladder mechanism, Fig. 5 [9-16]. Laxity in the uterosacral ligaments and/or perineal body may cause evacuation disorders [46].

\section{Characteristics of lumps (prolapse) in the vagina}

Initially, these only appear during straining. The three main causes of such 'lumps' are from the bladder (cystocoele "2"), uterus ("3"), and bowel (rectocele "4"), Fig. 9. These can only be accurately diagnosed by a vaginal examination, as not all lumps are accompanied by symptoms. Where symptoms accompany the prolapse, the symptoms may give an indication of where the problem is. As many symptoms have a peripheral neurological element in their causation, they may occur even with minimal prolapse. For example, according to the Diagnostic Diagram, Fig. 9, if a patient has nocturia, pelvic pain, and urgency, it is highly likely that she has weak posterior ligaments, even if there is no obvious prolapse evident on vaginal examination [23]. Diagnosis is by a process of deduction. A patient with a cystocele may have urgency, frequency, and abnormal emptying, but not nocturia and pelvic pain, which we have found to be specific for uterosacral ligament laxity.

\section{PART 4. TREATMENT}

\section{'Repair the structure and you will improve the function'}

New time efficient pelvic floor exercises strengthen muscles and ligaments

In 1995, we first conceived another approach to pelvic floor exercises. We knew from our ultrasound studies that the traditional Kegel methods were NOT addressing the posterior closure muscles, which stretch, rotate, and close the proximal urethra against the pubourethral ligament.

Our ultrasound studies had demonstrated that squatting exercises the very same muscles that close the urethra during coughing. We also reasoned that strengthening a pelvic muscle would also strengthen the ligament against which it contracted, and we knew from the surgery that it was ligament weakness that was causing the incontinence problems.

We therefore added squatting exercises to the traditional Kegel programme. Our target group of patients were those with symptoms which were bothersome, but not enough to require surgery. The results were dramatic. This patient group reported a more than $60 \%$ improvement in such symptoms as urgency, nocturia, pelvic pain, and abnormal bladder emptying. The most interesting observation, however, was that those patients who were cured, did not need to remember to contract their pelvic floor in advance. They coughed and did not leak [35-37].

A major problem with pelvic floor exercises is that women with young families and jobs, simply do not have time to perform them regularly. Even with our highly motivated group, the dropout rate was $50 \%$. Because of this, we concluded that the programme required re-analysis. We knew that the slow-twitch muscle fibers were the prime contributors to continence. Sitting on a "fitball" instead of a chair, is a very simple and effective exercise technique, as it requires a balanced upright position, with coordinated contraction of abdominal, back, and pelvic floor muscles. Unlike all traditional Kegel exercises, which require attention and time, sitting on a "fitball" requires no extra time to be set aside during the day. Initially we used the "fitball" method as an adjunctive exercise. In a short trial we found that the "fitball" method applied alone was well ac- cepted and the results seemed equally effective in the short-term, albeit in a small number of cases [38]. This method, promising and simple though it may be, awaits a rigorous scientific RCT with more traditional methods, using objective 24-hour pad test assessment.

\section{Surgery based on the Integral Theory System}

"Tension-free" techniques. Beginning in the late 1980s an entirely new surgical method for stress incontinence was introduced. Polypropylene tapes were placed around the middle part of the urethra (best known as the "TVT" operation) to reinforce the pubourethral ligaments,and then a little later, the posterior ligaments (infracoccygeal sacropexy, "PIVS") [5]. This method, now known as the "tension-free tape" technique, has revolutionized the treatment of stress incontinence (SI) and prolapse surgery. The operations are conducted via $1 \mathrm{~cm}$ incisions in the abdominal skin just above the pubic bone, groin or perineum. There is minimal pain, hospital stay is reduced to 1 or 2 days, and patients generally have few problems passing urine after the operation. The cure rate is high in the longer term. Later variations of these operations, include the transobturator (TOT) approach for SI (very successful), and the addition of mesh sheets to the TOT and PIVS techniques (not so successful). The only significant problem with all tape/mesh implant operations was partial or total rejection of the tape/mesh. More recently, an even less invasive method, the "minisling", has been introduced to address incontinence and organ prolapse [39-44].

Minislings - a new horizon for stress incontinence, and repair of cystocele, rectocele, and prolapse of the uterus

The TFS, Fig. 10, was the first minisling. It was applied in late 2003 to a patient with stress incontinence and uterovaginal prolapse. Since 2006, there has been a profusion of other minislings introduced for cure of stress incontinence, for example, TVT-Secur, Mini Arc, Ophira, and many others. The TFS midurethral sling is very effective for intrinsic sphincter defects, and 3-year data indicates very little deterioration of continence with time [31, 42, 43].

Because the TFS is a tensioned sling, it can also address not only stress incontinence and prolapse, but also many symptoms from the Pictorial Diagnostic, Algorithm (Fig. 9), including urgency, nocturia, abnormal emptying and pelvic pain.

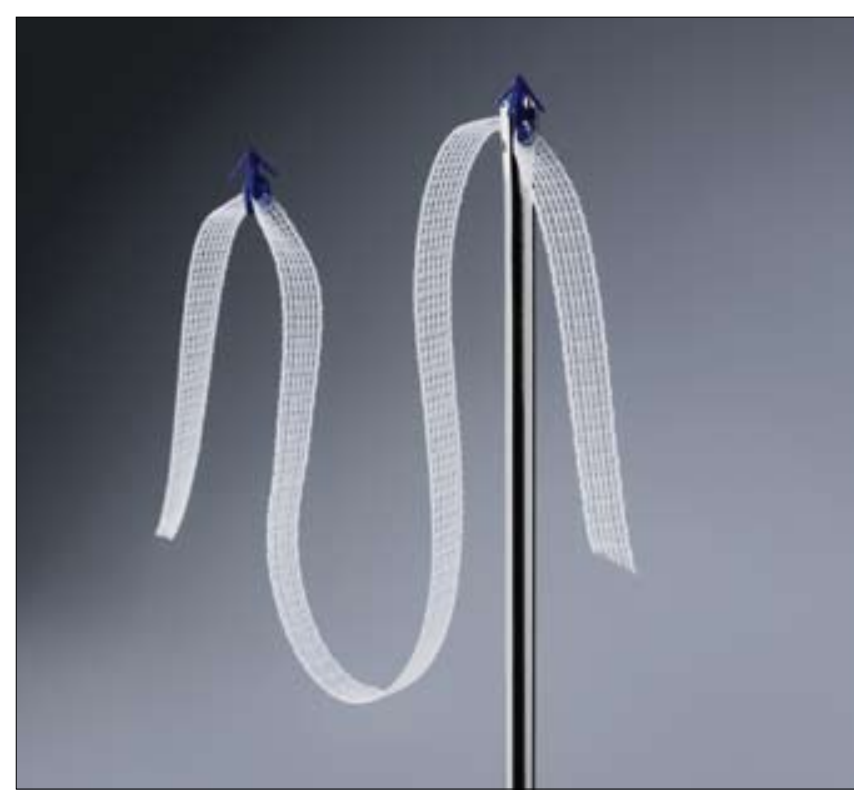

Fig. 10. TFS surgical system. The soft tissue anchor (blue) sits on the applicator. The tape (white) is a 'next generation" non-stretch lightweight macroporous monofilament polypropylene tape. The polypropylene tape passes through the unidirectional 'trapdoor' at the base of the anchor. This one-way system of tightening brings the laterally displaced ligaments and fascia towards the midline. 


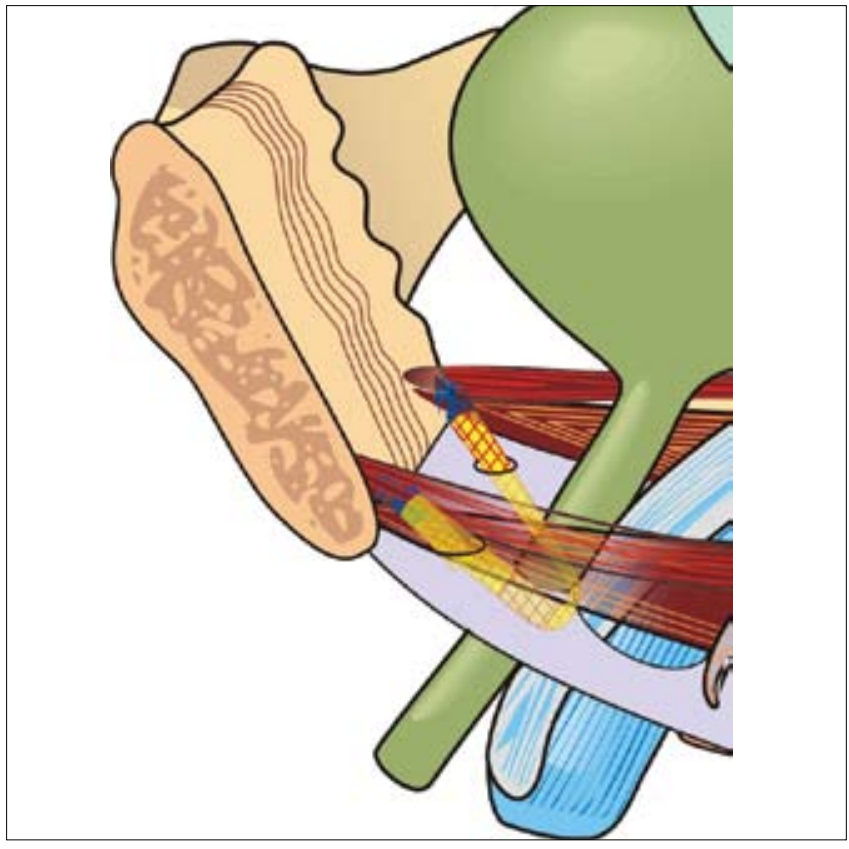

Fig. 11. The midurethral TFS tensioned minisling is inserted exclusively from the vagina at midurethra. It is tightened over an 18 gauge Foley catheter.

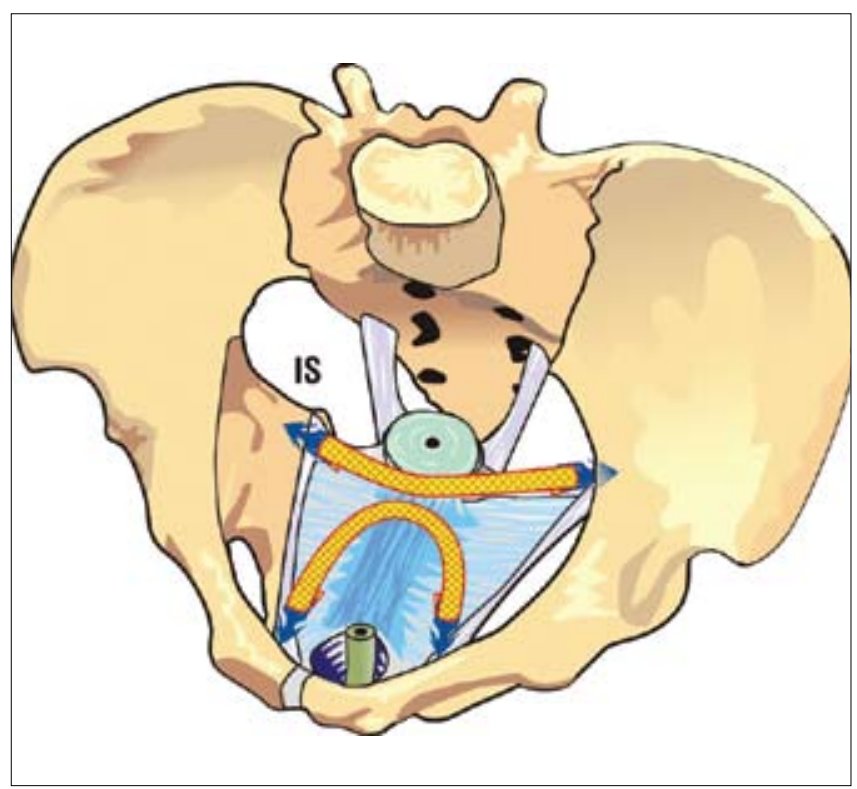

Fig. 12. TFS repair of cystocele. The horizontal cardinal ligament TFS sling when tightened approximates laterally displaced cardinal ligaments and fascia, creates an artificial collagenous anterior cervical ring, and re-attaches pubocervical fascia (blue) to the ring. It supports the proximal half of the vaginal membrane. The U-shaped "U-Sling", when tightened, restores the laterally displaced pubocervical fascia and supports the distal half of the vaginal membrane.

The TFS uses only small sections of monofilament tape, Figs.10-14, so it causes less tissue irritation. It uses a bioengineering principle similar to that of a domestic ceiling for cystocele and rectocele repair [41, 44]. The tape acts as the ceiling joist, and the vagina the plaster board. The TFS system for pelvic organ prolapse repair, Figs.11-14, avoids the spaces between rectum, bladder and vagina, and so it is not subject to the adhesive complications seen with large mesh such as dyspareunia and pain with defecation. As with all polypropylene implantations, the main complication is rejection of the tape by the body's immune mechanisms. However, this occurs only in a small percentage of patients, as only very small segments of tape are used, and the anchor prevents "slippage" into the wound, a major cause of erosion.

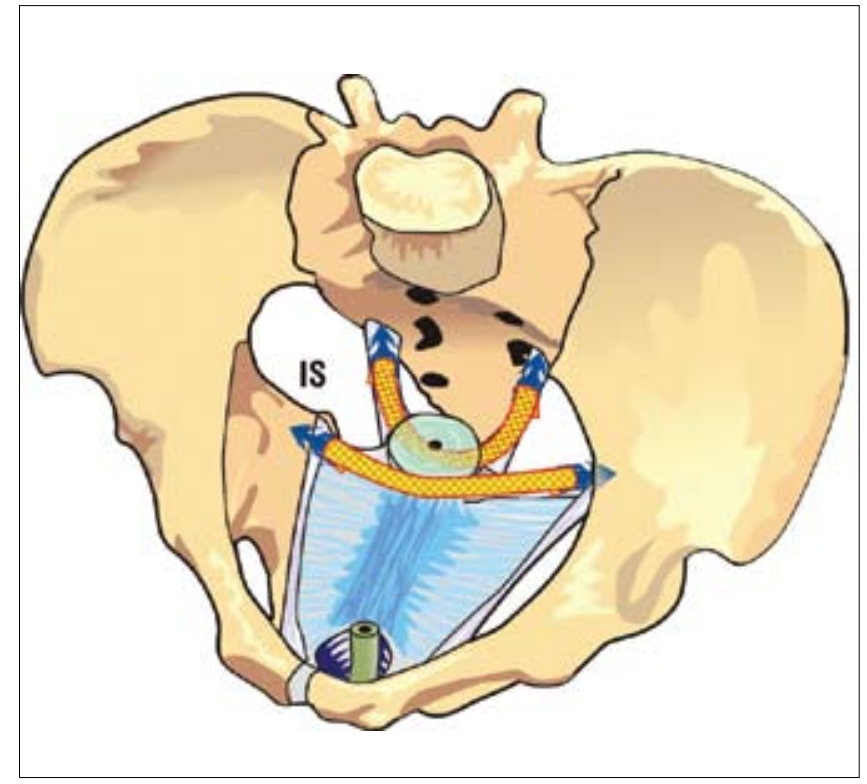

Fig. 13. TFS repair of uterine/apical prolapse. The TFS sling restores uterine position and axis by shortening cardinal with a transverse tape and uterosacral (USL) ligaments and fascia with a posterior tape.

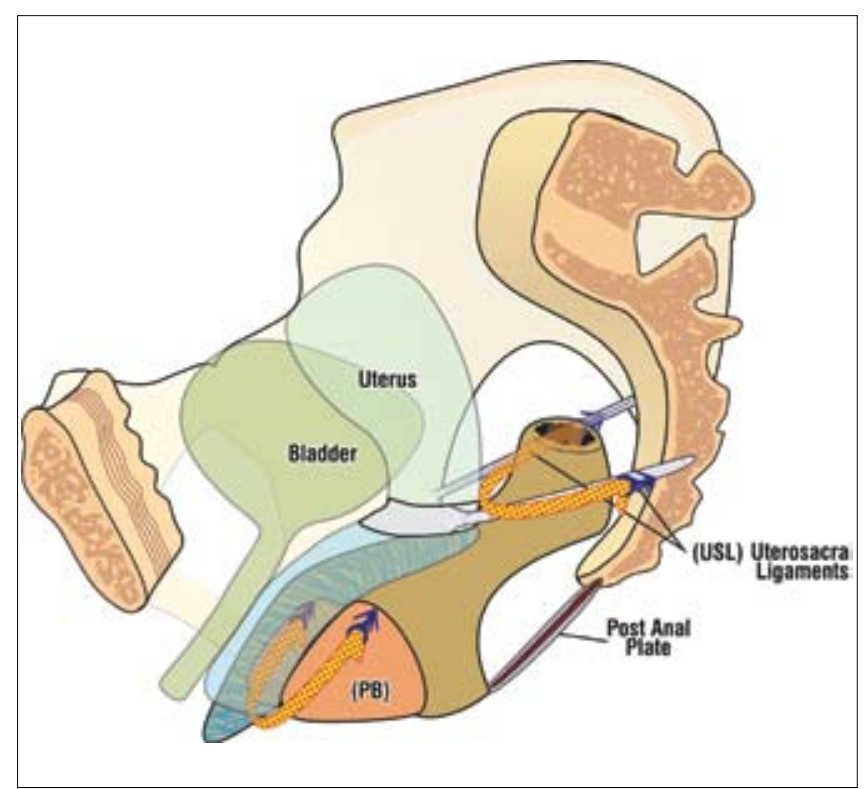

Fig. 14. TFS repair of rectocele. The TFS sling restores the anatomy of the posterior vaginal wall by shortening the uterosacral (USL) ligaments and fascia, and re-approximating the laterally displaced perineal body (PB).

Only a tensioned sling can reliably improve symptoms

Essential for cure of posterior zone symptoms with the posterior "tension-free" sling was restoration of tissue tension by approximation of laterally displaced tissues [5]. With the infracoccygeal sacropexy ("posterior IVS"), this could only be done with a suture, which was neither sufficiently strong, nor reliable.

The TFS minisling uses a one-way trapdoor system at its base to tighten loose ligaments and connective tissue. It was designed to precisely reconstruct and tension the five main structures that support the organs, pubourethral, ATFP, cardinal, uterosacral ligaments, and perineal body. The Theory explains symptom relief as follows; the now tensioned ligaments provide a firm anchoring point for the pelvic muscles to contract efficiently to close and open the urethra and anus, restoring continence and evacuation; 
the tensioned anterior vaginal wall now supports the bladder base stretch receptors to relieve urgency; the tensioned uterosacral ligaments support the afferent nerve endings to relieve pelvic pain.

Application of slings for anorectal function and dysfunction

Application of slings at the site of the pubourethral and/or uterosacral ligaments has been found to cure/greatly improve $>80 \%$ of patients with idiopathic fecal incontinence [41, 44-47]. Patients with anterior rectal wall intussusception and anorectal evacuation problems ("constipation") have been cured with posterior slings and perineal body repair. [46]. The anatomical basis for this is explained in a series of 13 works available online at www.pelviperineology.org, September 2008.

\section{CONCLUSIONS}

Organ prolapse and symptoms are related, and both are mainly caused by laxity in the four main suspensory ligaments and perineal body. Restoration of ligament/fascial length and tension is required to restore anatomy and function.

\section{REFERENCES}

1. Petros PE, Ulmsten U: An Integral Theory of female urinary incontinence. Acta Obst Gynecol Scand1990; Suppl. 153, Vol. 69: 1-79.

2. Petros PE, Ulmsten U: An Integral Theory and its Method, for the Diagnosis and Management of female urinary incontinence. Scandinavian Journal of Urology and Nephrology 1993; Vol. 7, Suppl. 153: 1-93.

3. Petros PE: The International Continence Society and Integral Theory systems for management of the incontinent female -a comparative analysis. Pelviperineology 2007; 26: 25-29

4. Petros PE, Ulmsten U, Papadimitriou J: The Autogenic Neoligament procedure: A technique for planned formation of an artificial neo-ligament. Acta Obstet Gynecol Scand 1990; Vol. 69, Suppl. 153, 1990, pp. 43-51.

5. Petros PE: New ambulatory surgical methods using an anatomical classification of urinary dysfunction improve stress, urge, and abnormal emptying. Int J Urogynecology 1997; 8; 5: 270-278.

6. Petros PE: Influence of hysterectomy on pelvic floor dysfunction. Lancet 2000; 356: 1275.

7. Petros PE: Ulmsten U, Role of the pelvic floor in bladder neck opening and closure: I muscle forces. Int J Urogynecol and Pelvic Floor 1997; 8: 74-80.

8. Petros PE, Ulmsten $\mathrm{U}$ : Role of the pelvic floor in bladder neck opening and closure: // vagina. Int J Urogynecol and Pelvic Floor 1997; 8: 69-73

9. Petros PE, Swash M: The Musculoelastic Theory of anorectal function anddysfunction. J Pelviperineology 2008; 27: 89-93.

10. Petros PE, Swash M: Directional muscle forces activate anorectal continence and defecation in the female. J Pelviperineology 2008; 27: 94-97.

11. Petros PE, Swash MA: Direct test for the role of the pubourethral ligament in anorectal closure. J Pelviperineology 2008; 27: 98.

12. Petros PE, Swash M: Reflex contraction of the levator plate increases intraanal pressure, validating its role in continence. J Pelviperineology 2008; 27: 99.

13. Petros $\mathrm{PE}, \mathrm{Swash} \mathrm{M}$ : Abdominal pressure increase during anorectal closure is secondary to striated pelvic muscle contraction. J Pelviperineology 2008; 27: 100-101.

14. Petros PE, Swash M: A prospective endoanal ultrasound study suggests that internal anal sphincter damage is unlikely to be a major cause of fecal incontinence. J Pelviperineology 2008; 27: 102.

15. Petros $\mathrm{PE}$, Swash M: Correction of abnormal geometry and dysfunction by suspensory ligament reconstruction gives insights into mechanisms for anorectal angle formation. J Pelviperineology 2008; 27: 103-104.

16. Petros $\mathrm{PE}$, Swash $\mathrm{M}$ : Role of puborectalis muscle in anal continencecomments on original $4 D$ pelvic ultrasound data from Chantarasorn \& Dietz. J Pelviperineology 2008; 27: 105.
17. Petros PE, Swash M, Kakulas B: Stress urinary incontinence results from muscle weakness and ligamentous laxity in the pelvic floor. J Pelviperineology 2008; 27: 107-109.

18. Petros $\mathrm{PE}, \mathrm{U}$ Imsten U: Bladder instability in women: A premature activation of the micturition reflex. Neurourology and Urodynamics 1993; 12: 235-239.

19. Petros PE: Detrusor instability and low compliance may represent different levels of disturbance in peripheral feedback control of the micturition reflex. Neurourol and Urod 1999; 18: 81-91.

20. Bush MB, Petros PEP, Barrett-Lennard BR: On the flow through the human urethra. Biomechanics 1997; 30 (9): 967-969.

21. Petros PE, Bush MB: A mathematical model of micturition gives new insights into pressure measurement and function. Int J Urogynecology 1998; 9: 103-107.

22. Petros PE, Chapter 6- Mapping the Dynamics of Connective Tissue Dysfunction Urodynamics - An Anatomical Perspective, in The Female Pelvic Floor, Springer Heidelberg $3^{\text {rd }}$ edition, 2010, pp. 227-257.

23. Petros PEP, Richardson PA: TFS posterior sling improves overactive bladder, pelvic pain and abnormal emptying, even with minor prolapse - a prospective urodynamic study. Pelviperineology 2010; 29: 52-55.

24. Rechberger T, Uldbjerg N, Oxlund $\mathrm{H}$ : Connective tissue changes in the cervix during normal pregnancy and pregnancy complicated by a cervical incompetence. Obstets \& Gynecol 1988; 71: 563-567.

25. Peacock EE. Structure, synthesis and interaction of fibrous protein and matrix. Wound Repair, 1984, $3^{\text {rd }}$ Edition, Publishers WB Saunders Co, Philadelphia, pp. 56-101.

26. Ulmsten U, Falconer C. Connective tissue in female urinary incontinence. Curr Opin Obstet Gynecol 1999; 11: 509-515.

27. Falconer C, Ekmanordeberg G, Ulmsten U, et al: Changes in paraurethral connective tissue at menopause are counteracted by estrogen. Maturitas 1996; 24 (3): 197-204.

28. Caruso D, Gomez Ch, Gousse A: Medical management of stress urinary incontinence: Is there a future? Current Urology Report 2009; 10 (5): 401-407.

29. Gordon AM, Huxley AF, Julian FJ: The variation in isometric tension with sarcomere length in vertebrate muscle fibres. J Physiol 1996; 184: 170-192.

30. Huisman AB: Aspects on the anatomy of the female urethra with special relation to urinary continence. Contrib Gynecol Obstet 1983; 10: 1-31.

31. Sekiguchi $\mathrm{Y}$, Kinjyo M, Inoue $\mathrm{H}$ et al: Outpatient mid urethral tissue fixation system sling for urodynamic stress urinary incontinence. The Journal of Urology 2009; 182 (6): 2810-2813.

32. Petros PE and Bornstein J: Vulvar vestibulitis may be a referred pain arising from laxity in the uterosacral ligaments - a hypothesis based on 3 prospective case reports. ANZJOG 2004; 44: 483-486.

33. Bornstein J, Zarfati, D, Petros PEP: Causation of vulvar vestibulitis. ANZJOG 2005; 45: 538-541.

34. Butrick CW, Sanford D, Hou Q, Mahnken JD: Chronic pelvic pain syndromes: clinical, urodynamic, and urothelial observations. Int Urogynecol J Pelvic Floor Dysfunct 2009; 20: 1047-1053.

35. Petros PE and Skilling PM: Pelvic floor rehabilitation according to the Integral Theory of Female Urinary Incontinence - First report. Eur J Obstet Gynecol Reprod Biol 2001; 94; 2: 264-269.

36. Petros PE, Skilling PM: The physiological basis of pelvic floor exercises in the treatment of stress urinary incontinence. Br J Obstet Gynaecol 1999; 106: 615-616.

37. Skilling PM, Petros PE: Synergistic non-surgical management of pelvic floor dysfunction: second report. Int J Urogyne 2004,15: 106-110.

38. Petros PE, Chapter 5 - Non-surgical management, in The Female Pelvic Floor, Springer Heidelberg $3^{\text {rd }}$ edition, 2010, pp. 219-225.

39. Petros PEP, Richardson PA: The midurethral TFS sling - a 'micro-method' for cure of stress incontinence - preliminary report. ANZJOG 2005; 45: 372-375.

40. Petros PEP, Richardson PA: The TFS posterior sling for repair of uterine/vault prolapse - a preliminary report. ANZJOG 2005; 45: 376-379. 
41. Abendstein $B$, Petros PE, Richardson PA: Ligamentous repair using the Tissue Fixation System confirms a causal link between damaged suspensory ligaments and urinary and fecal incontinence. J. Pelviperineology 2008; 27: 114-117.

42. Sivaslioglu AA, Unlubilgin $\mathrm{E}_{1}$ Aydogmus et al: A Prospective Randomized Comparison of Transobturator Tape and Tissue Fixation System Minisling in the Treatment of Female Stress Urinary Incontinence: 3 Year Results. J Pelviperineology 2010 (in press).

43. Petros PE, Richardson PA: A 3 year follow-up review of uterine/vault prolapse repair using the TFS minisling. RANZJOG 2009, 49; 4: 439-440.

44. Inoue $H$, Sekiguchi $Y$, Kohata $Y$ et al: Tissue Fixation System (TFS) to repair uterovaginal prolapse with uterine preservation: A preliminary report on perioperative complications and safety. J Obstet. Gynaecol. Res. April 2009; 35 (2): 346-353.

45. Hocking I: Experimental Study No. 9: Double incontinence, urinary and fecal, cured by surgical reinforcement of the pubourethral ligaments. J Pelviperineology 2008; 27: 110.
46. Abendstein B, Brugger BA, Furtschegger A et al. Role of the uterosacral ligaments in the causation of rectal intussusception, abnormal bowel emptying, and fecal incontinence-a prospective study. J Pelviperineology 2008; 27: 118-121.

47. Petros $P E$, Richardson PA: Fecal incontinence cure by surgical reinforcement of the pelvic ligaments suggests a connective tissue aetiology. J Pelviperineology 2008; 27: 111-113.

\section{Correspondence}

Peter PEP Petros

31/29, Elizabeth Bay Rd.

Elizabeth Bay

NSW 2011, Australia

phone: +61 411181731

pp@kvinno.com 